\title{
The Effect of some Plant Extracts on the Control of Bacteria Isolated from the Iraqi Currency
}

\author{
Khelood Abd Al-Majeed Mohammed Jafer \\ Department of Community Health, Technical Institute Babel, University of Al-Furat Al-Awsat 51015 \\ Babel, Iraq \\ Majeed_khulood@yahoo.com
}

Submission date:- 2/4/2018 Acceptance date:- 16/5/2018 Publication date:- 12/11/2018

Keywords: Nigella satia, Ricinus communis,Iraqi paper currency notes.

\begin{abstract}
This research was conducted at the technical institute Babylon/ department of community health /medical microbiology lab, to evaluate the efficiency of some plant extract in order on bacterial inhibition which were not recorded the bacteria which isolated from the money.

The results showed that the extract of the hot water for the plant black pill has a high efficiency in the inhibition of bacteria on nutrient agar at the concentration of the following 25-50-75-100 mg/ml,respectively . They were given of inhibition $33.3 \mathrm{~mm}, 41.6 \mathrm{~mm}, 66.6 \mathrm{~mm}, 91.6 \mathrm{~mm}$. Respectively which is compared with a hot water extract of the plant of castor beans which not record any inhibition of the bacteria.
\end{abstract}

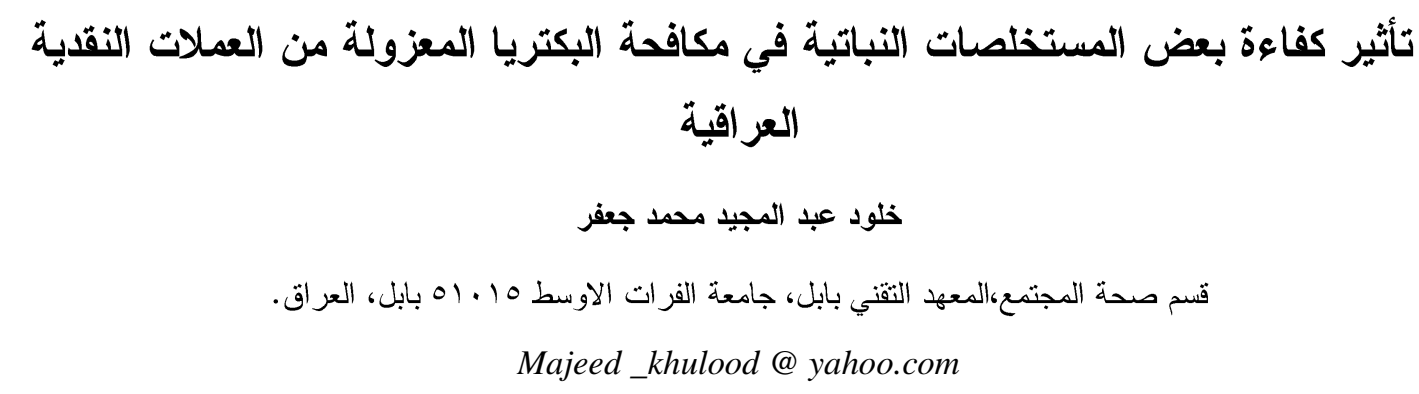

أجري هذا البحث في المعهد التقني بابل لقسم صحة المجتمع، مختبر الأحياء المجهرية لتقويم كفاءة بعض المستخلصات النباتية في مكافحة

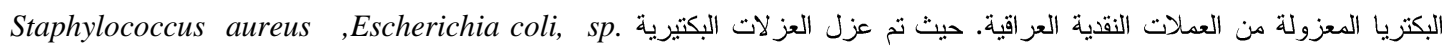

.Klebsiella

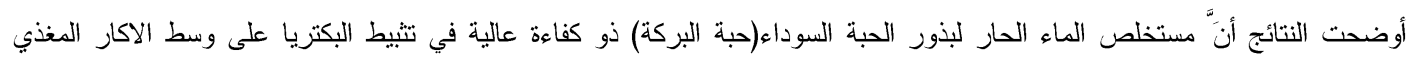

Nutrient agar

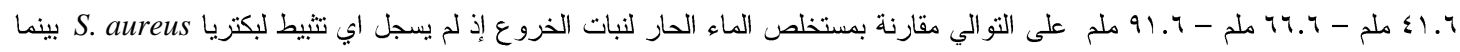

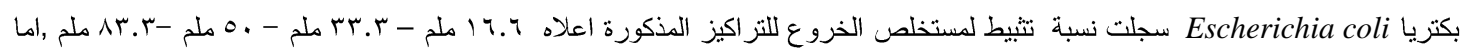

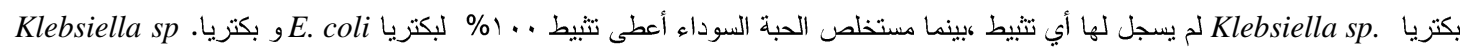
في التزكيز . . 1 ملغم/ملم. الكلمات الا الة: الحبة السوداء، الخروع،العملة، الورقية العر اقية المتداولة. 
نظراً لأهمية العملات النقدية في الحياة الاقتصادية لأفراد المجتمع ونتيجة لتداول هذه العملات بين الأيدي لمختلف أفراد المجتمع فأنها

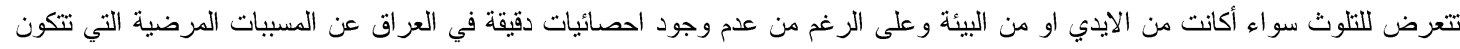

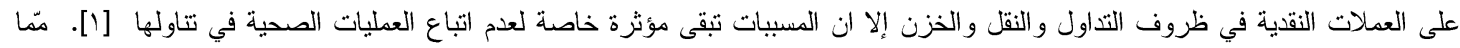

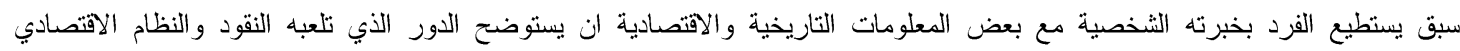

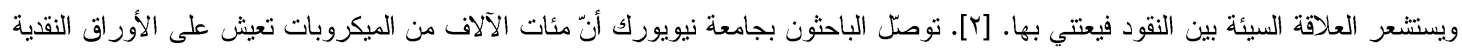

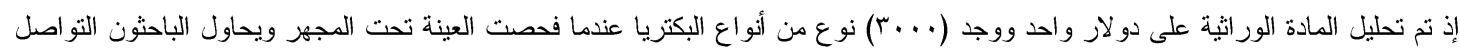

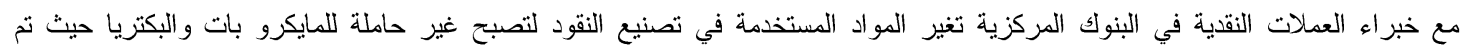

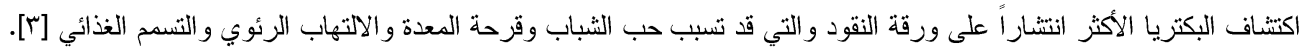

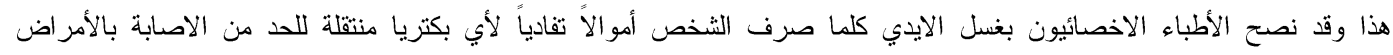

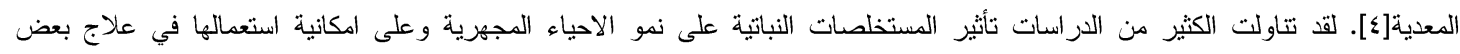
الأمر اض الناتجة من الاصابات الميكروبية المختلفة، فعلى الصعيد المحلي أجريت دراسات عدة حول تأثير الدستخلصات النباتية على الميكروبات

وقد تناولنا تأثير مستخلصات الخروع والحبة السوداء وتم انتخاب هذه النباتات لتوفرها بكثرة في البيئة المحلية ولندرة الدراسات حول

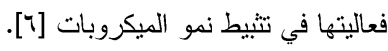

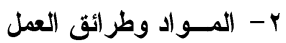

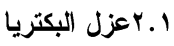

تم أخذ .. أمسحة من فئات مختلفة من العملات النقية بوساطة swab وزرعها في الاطباق الزراعية الحاوية على وسط الماكونكي

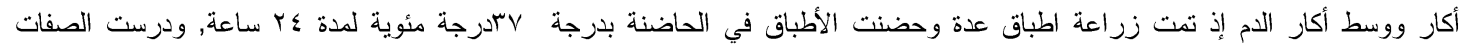

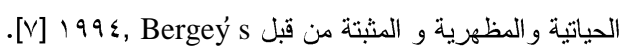

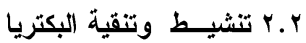

تم وضع كمية من الملح الفسيولوجي normal saline في انبوبة اختبار نظيفة ثم وضعنا كمية قليلة من البكتريا الموجودة في الطبق الذي وتي

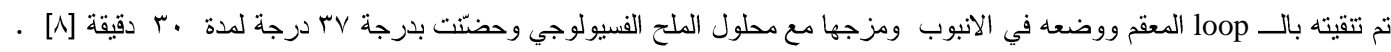

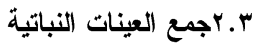

جمعت العينات النباتية من أوراق شجر الخروع وبذور الحبة السوداء من الأسواق المحلية لمحافظة بابل ونقلت الى المختبر وتم غسل

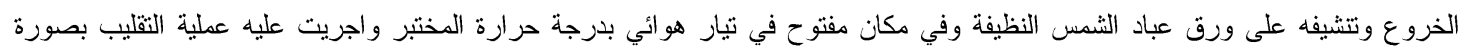

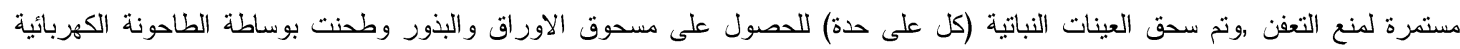

ووضعت في اكياس جافة ونظيفة لاستعمالها في الاستخلاص و التثيبط و الدراسة الكيميائية للبكتريا [بآ].

ع.بتحضير المستخلصات النباتية

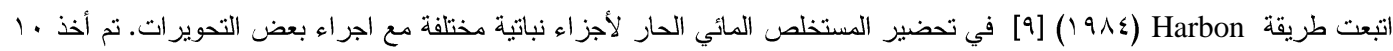

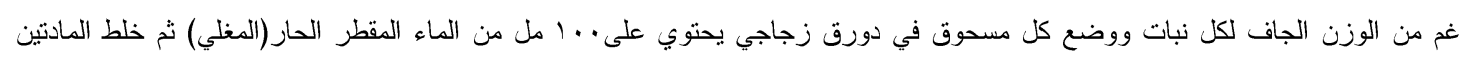

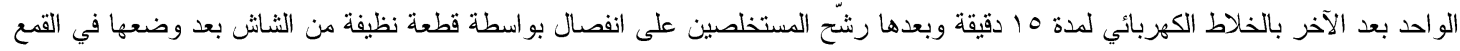
الزجاجي الموضوع في دورق لوضع المحلول للحصول على الستخلص النباتي المطلوب لكليهما [بآ].

ه.r.أثير المستخلصات النباتية على البكتريا

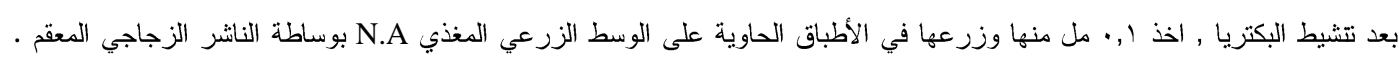

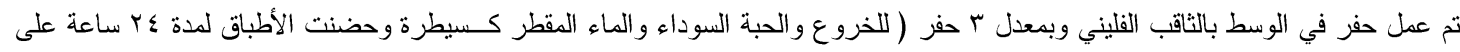
درجة حرارة VT درجة مئوية["]]. وتم حساب نسبة التثئيط حسب المعادلة التالية 
معل قطر التثيط فح، اطباق المقار نة - معدل قطر التثيط فه، اطباق المعاملة

$[1 \cdot] 1 \cdots x$

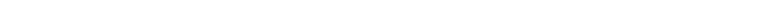

معدل قطر التثيط في اطباق المقارنة

نسبة التثبيط

r- النتائج و المناقشة

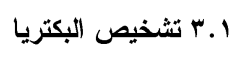

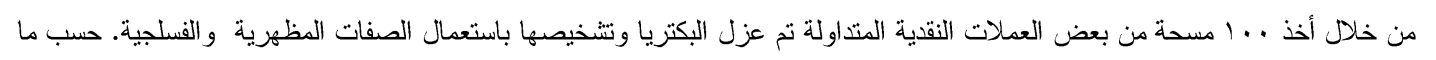

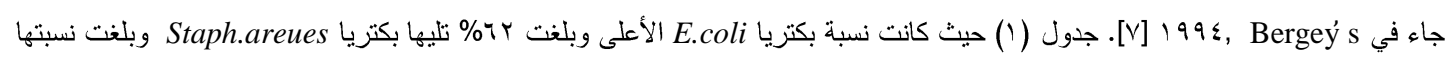

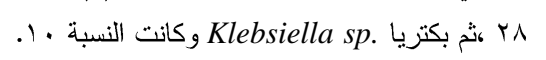

\section{r.r r تأثير تر اكيز مختلفة من المستخلصات في تثبيط نمو البكتريا \\ ا. مستخلص الماء الحار لبذور نبات الحبة السوداء}

Staphylococcus اظهرت نتائج الدراسة تأثير التزر اكيز المختلفة من مستخلص الماء الحار لبذور نبات الحبة السوداء إذ أعطت تثيط لبكتريا نبureus

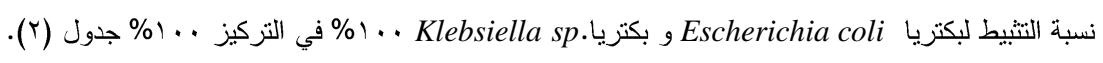

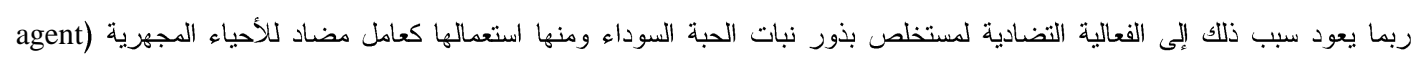

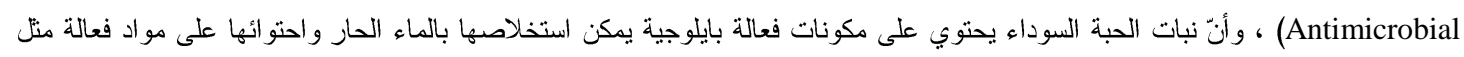

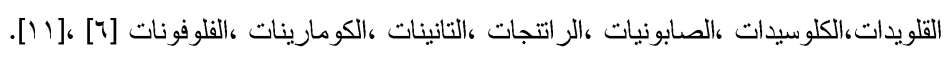

\section{r ب تأثير مستخلص الماء الحار لورق نبات الخروع}

أظهرت نتائج الدراسة عدم تأثير التراكيز المختلفة لمستخلص نبات الخروع في نمو البكتريا

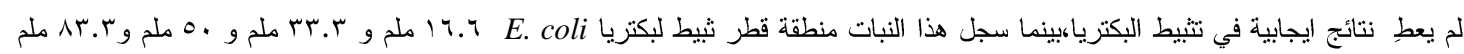

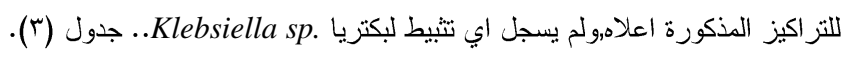
ويعود السبب لإحتواء اور اق الخروع على مجموعة التانينات المكثفة والمتحللة ووجود المركبين - (-) أبيكاتاثين و (士) - كاتاثثين وهو

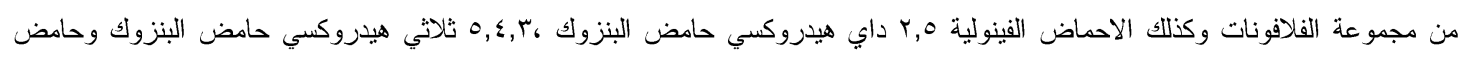

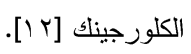

جدول(1) أنواع البكتريا المعزولة.

\begin{tabular}{|c|c|c|}
\hline نسبة الإصابة & عدد العينات & نوع البكتريا \\
\hline$\%$ \%^ & $r \wedge$ & Staph.areues \\
\hline$\% \pi r$ & 74 & E.coli \\
\hline$\%$ Yo & 1. & Klebsiella sp. \\
\hline$\% 1 \ldots$ & $1 \ldots$ & \\
\hline
\end{tabular}


جدول(ץ) تأثير تر اكيز مختلفة من مستخلص الماء الحار لنبات الحبة السوداء على البكثريا المعزولة من العملات النقدية.

\begin{tabular}{|c|c|c|c|c|}
\hline \multicolumn{4}{|c|}{ نسبة التشيط \% } & \\
\hline OP ملغم/ملم & • 0 ملغم/ ملم & & . . 1 ملغم/ ملم & \\
\hline 91.6 & 66.6 & 41.6 & 33.3 & Staph.areues \\
\hline$V V$ & 70 & $\leqslant 0$ & $1 \cdots$ & E.coli \\
\hline$\wedge$. & 70 & 07 & $1 \cdots$ & Klebsiella sp. \\
\hline
\end{tabular}

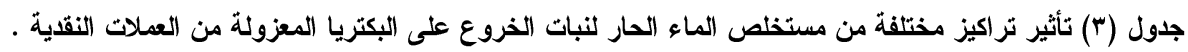

\begin{tabular}{|c|c|c|c|c|}
\hline \multicolumn{4}{|c|}{ نسبة التبيط \% } & \\
\hline OY ملغم/ ملم & •0 ملغم/ ملح & VO ملغم/ ملح & ... (ملغم/ ملم & \\
\hline$\cdot$ & · & · & 0 & Staph.areues \\
\hline 83.3 & 50 & 33.3 & 16.6 & E.coli \\
\hline · & $\cdot$ & $\cdot$ & $\cdot$ & Klebsiella sp. \\
\hline
\end{tabular}

1- مستخلص الماء الحار لبذور نبات الحبة السوداء لها القدرة على تثيط البكتريا الموجودة في النقود. r- مستخلص الماء الحار لورق نبات الخروع ليس له القدرة على تثبيط البكتريا.

\section{CONFLICT OF INTERESTS}

There are no conflicts of interest.

[1] عباس، ميسون صباح."دراسة حساسية بعض البكتريا الممرضةتلمضادات الحيوية والمستخلصات النباتية"، رسالة ماجستير، كلية الطب

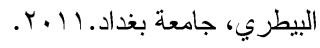

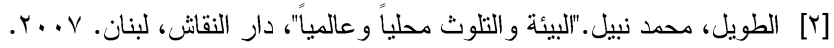

[ب] عبد، هدى سهيل."التلوث البكتيري للعمله الورقيه العراقيه المتداوله ومقاومة البكتريا الممرضه للمضادات الحيويه. المجله العراقيه للعلوم

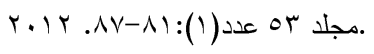

[4] Sharma,A.and Dhanshiree,B".Screening of currency in circulation for bacterial contamination" .Current sci.,100 (6) :822-825. 2011.

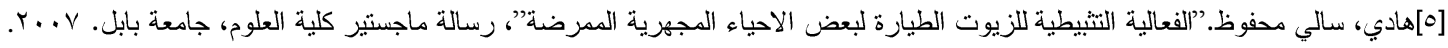

[־] المشهدي، خلود عبد المجيد محمد جعفر.” الفعالية الحياتية لبعض المستخلصات النباتية على البكتريا المسببة للامر اض"، رسالة ماجستير،

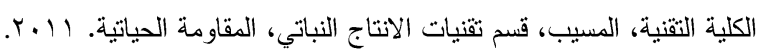

[7] Bergey S. "Manual of Determinative Bacteriology". $9^{\text {th }}$.Williams and Wilkins (USA). 1994.

[N] الأهب، ازهار عمران لطيف. "الفعالية التضادية لمستخلصات نباتية عراقية في بعض البكتريا الممرضة” .رسالة ماجستير .كلية العلوم.قسم 
[9] Harbon,J.B."Phyto Chemical Methods. Aguide to Moderm". Techniques of Plant Analysis. London. Newyourk. Capman and Hall .1984.

[• (1] المعموري، ايناس عباس خير الله.تقييم كفاءة بعض العو امل المضادة للفطريات والخمائر الانتهازية المعزولة من بعض مستتفيات محافظة

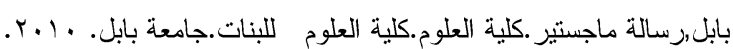

[11] Lonard, RT. Little. CR. "Weeds in South Texas and Northern Mexico". Lubbock. Everitt, J.H. Texas Tech .University press. 2007.

[ 1 1 خوجلي،عائشة بنت محمد علي. دراسة مقارنة على البيئة الذاتية لنبات الخروع (Ricinus Communus) أحد النباتات الإقتصادية النامية

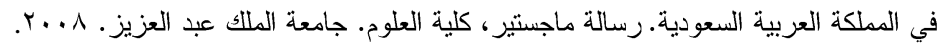

